\title{
Rowing Increases Stroke Volume and Cardiac Output to a Greater Extent Than Cycling
}

\author{
P. HORN ${ }^{1}$, P. OSTADAL ${ }^{2}$, B. OSTADAL ${ }^{3}$
}

${ }^{1}$ Department of Physical Education, Second Faculty of Medicine, Charles University in Prague, Prague, Czech Republic, ${ }^{2}$ Department of Cardiology, Cardiovascular Center, Na Homolce Hospital, Prague, Czech Republic, ${ }^{3}$ Department of Developmental Cardiology, Institute of Physiology, Academy of Sciences of the Czech Republic, Prague, Czech Republic

Received June 14, 2014

Accepted September 4, 2014

On-line October 15, 2014

\section{Summary}

Exercise stimulates increases in heart rate (HR), stroke volume (SV) and cardiac output (CO). These adaptive mechanisms are strongly dependent on the type of exercise. Both rowing and cycling are widely used for physical training worldwide; however, evidence regarding the differences in major hemodynamic parameters during rowing and cycling remains insufficient. Ten healthy male volunteers were randomly assigned to perform either a rowing or cycling exercise. After 20 min rest, the group who had rowed first performed the cycling exercise and vice versa. Exercise was performed at a power-to-weight ratio of $2 \mathrm{~W} / \mathrm{kg}$ for $2 \mathrm{~min}$. HR, SV, CO and blood pressure (BP) were measured noninvasively using pulse-wave analysis at baseline and immediately after each exercise. HR, SV and CO were significantly higher after exercise than at rest. Whereas HR was comparable between rowing and cycling, SV and CO were significantly higher after rowing than after cycling. BP was comparable among all three measurements. Rowing increased SV and $\mathrm{CO}$ to a greater extent than cycling, whereas HR and BP were not influenced by the type of exercise. Our data suggest that rowing leads to more extensive stimulation of cardiac contractility and/or decreases in peripheral vascular resistance compared with cycling.

\section{Key words}

Cardiac output $\bullet$ Cycling $\bullet$ Heart rate $\bullet$ Rowing $\bullet$ Stroke volume

\section{Corresponding author}

P. Ostadal, Cardiovascular Center, Department of Cardiology, Na Homolce Hospital, Roentgenova 2, 15030 Prague, Czech Republic. Fax: 420-257272974. E-mail: ostadal.petr@gmail.com

\section{Introduction}

The assessment of cardiac function, particularly cardiac output (CO), during exercise is essential for the evaluation of cardiovascular factors that may limit oxygen transport. Measures of $\mathrm{CO}$ enable researchers to develop insight into the physiological responses and mechanisms of adaptation induced by physical training, sedentary lifestyle or chronic disease. $\mathrm{CO}$ - the product of stroke volume (SV) and heart rate (HR) - represents the body's ability to meet the metabolic demands of exercise; it may increase by five- to sixfold when an individual is exerting maximal effort during exercise (Warburton et al. 1999a). Coordinated autonomic nervous system function (characterized by rapid and sustained parasympathetic withdrawal coupled with sympathetic activation) is required for this to occur. Maximal HR varies innately among individuals and decreases with age. The increase in HR is responsible for the majority of the augmentation of $\mathrm{CO}$ during exercise, and peak HR is a fundamentally limiting factor of peak exercise capacity in healthy individuals. However, maximal HR does not increase with exercise training; thus, it is not considered to be an adaptable property. In contrast, SV - both at rest and during exercise - increases with prolonged exercise training (Baggish 2013). It rises during exercise due to increases in ventricular enddiastolic volume and, to a lesser degree, due to sympathetically mediated reductions in end-systolic volume (Rowell et al. 1986). Currently, the degree to which each of these factors contributes to SV 
augmentation during exercise remains unclear.

Hemodynamic conditions - specifically, changes in $\mathrm{CO}$ and peripheral vascular resistance due to exercise vary widely across sporting disciplines. Although some overlap exists, exercise can be separated into two types with defining hemodynamic differences. Isotonic exercise, also referred to as endurance exercise, involves sustained elevations in $\mathrm{CO}$ with normal or reduced peripheral vascular resistance. This type of exercise primarily represents a volume challenge for the heart, which affects all four chambers. Activities that involve isotonic exercise include long-distance running, Nordic walking and swimming (Baggish 2013). According to Morganroth et al. (1975), athletes involved in sports with a high dynamic component develop predominantly increased left ventricular chamber size, with a proportional increase in wall thickness caused by volume overload (i.e., eccentric left ventricular hypertrophy). In contrast, isometric exercise, also referred to as strength training, leads to increased peripheral vascular resistance, and normal or only slightly elevated $\mathrm{CO}$. This increase in peripheral resistance causes transient but potentially marked systolic hypertension and left ventricular afterload. Strength training is the dominant form of exercise in activities such as weightlifting, and track and field throwing events. Athletes involved in mainly static or isometric exercise develop predominantly increased left ventricular wall thickness, with no change in left ventricular chamber size (i.e., concentric left ventricular hypertrophy). Many sports, including popular team-based activities such as soccer, basketball and ice hockey, involve significant elements of both endurance and strength exercise: both left ventricular weight and cavity size appear to be enlarged in athletes who engage in these activities.

Cycling and rowing are also included in this group (Kuchynka et al. 2010, Pluim et al. 2000). Both rowers and cyclists exhibit the largest left ventricular weight compared with other elite athletes, suggesting that the combination of strength and endurance training in rowing and cycling is a particularly potent stimulus for myocardial adaptation (Naylor et al. 2008, Pelliccia et al. 1991). However, the evidence regarding the effects of these two types of exercise on acute changes in major hemodynamic parameters remains insufficient. The aim of the present study was, therefore, to compare HR, SV and $\mathrm{CO}$ (measured using a noninvasive method based on pulse-wave analysis) during exercise involving rowing and cycling. Both are activities involving combined endurance and strength exercise and - as stated above represent potent stimuli for cardiac function.

\section{Methods}

\section{Subjects}

The study population consisted of 10 healthy male volunteers with a mean age of 23 years. All subjects were engaged in regular leisure sports activities, were free from known cardiovascular disease, were normal according to physical examination and had normal cardiac anatomy (assessed using two-dimensional echocardiography). The present study was approved by the Na Homolce Hospital Ethics Committee (Prague, Czech Republic) and all participants provided informed consent.

\section{Hemodynamic measurements}

Hemodynamic parameters were evaluated noninvasively using a pulse-wave analysis system (Vicorder; Skidmore Medical Limited, Bristol, United Kingdom). Blood pressure, $\mathrm{HR}, \mathrm{SV}$ and $\mathrm{CO}$ were recorded.

\section{Study protocol}

After baseline hemodynamic values at rest were measured, the subjects were randomly assigned to perform either a cycling (Pro Energy PU 300; Impulse Health Tech Ltd, Jimo City, Qingdao, Shandong, China) or a rowing exercise (E 520 Fluid Rower; First Degree

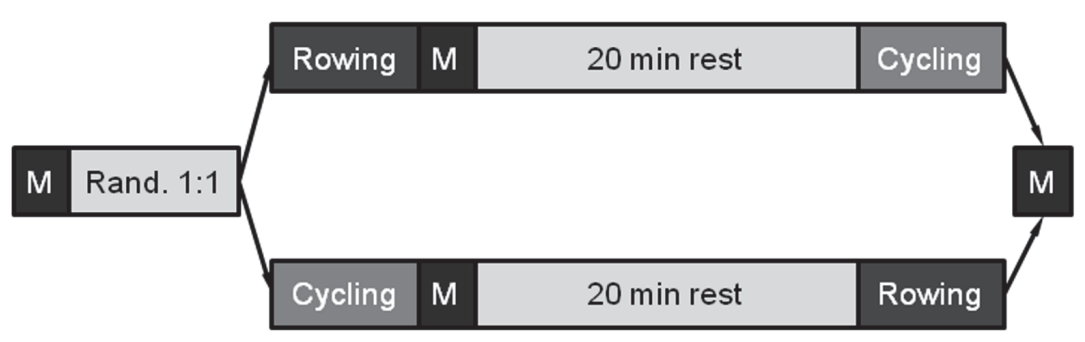

Fig. 1. Schematic illustration of study protocol. M: Hemodynamic measurement; Rand.: Randomly assigned to groups 
Fitness, Houten, The Netherlands) at a power-to-weight ratio of $2 \mathrm{~W} / \mathrm{kg}$ for $2 \mathrm{~min}$. Randomization was conducted by choosing participant names from a box containing all 10 names; five participants were randomly assigned to cycle first and five to row first. Immediately after the initial period of exercise, a second hemodynamic measurement was performed, followed by $20 \mathrm{~min}$ rest. Subsequently, the individuals who were randomly assigned to cycle first performed the rowing exercise and vice versa. The final hemodynamic measurement was performed immediately after the second exercise (Fig. 1).

\section{Statistical analysis}

Data are expressed as mean $\pm \mathrm{SD}$. Data from each type of exercise were pooled. Baseline, rowing and cycling exercise values were compared using a repeatedmeasures one-way ANOVA with Tukey's multiple comparisons test; $\mathrm{P}<0.05$ was considered to be statistically significant.

\section{Results}

Changes in HR were highly significant $(\mathrm{P}=0.0003$; Fig. 2A). The baseline HR (69.4 \pm 9.1 beats/min) significantly increased following each type of exercise: to $82.6 \pm 11.5$ beats $/ \mathrm{min}$ after rowing $(\mathrm{P}<0.05$ versus baseline) and to $78.5 \pm 8.9$ beats $/ \mathrm{min}$ after cycling $(\mathrm{P}<0.05$ versus baseline $)$. The $\mathrm{HR}$ values measured immediately after each type of exercise were comparable $(\mathrm{P}>0.05)$.

Significant changes were also observed for SV $(\mathrm{P}=0.0001$, Fig. 2B). This parameter was significantly lower at rest (baseline value $85.5 \pm 20.6 \mathrm{ml}$ ) than after exercise: this parameter reached $137.8 \pm 40.5 \mathrm{ml}$ after rowing $(\mathrm{P}<0.05$ versus baseline $)$ and $100.3 \pm 27.0 \mathrm{ml}$ after cycling $(\mathrm{P}<0.05$ versus baseline). The $\mathrm{SV}$ after rowing was significantly higher compared with after cycling $(\mathrm{P}<0.05)$.

Similarly, different results were observed with regard to $\mathrm{CO}(\mathrm{P}=0.0003)$. $\mathrm{CO}$ was significantly lower at rest (baseline $6.1 \pm 2.0 \mathrm{l} / \mathrm{min})$ than after rowing $(11.7 \pm 4.5$ $1 / \mathrm{min} ; \mathrm{P}<0.05$ versus baseline) or cycling $(7.9 \pm 2.91 / \mathrm{min}$; $\mathrm{P}<0.05$ versus baseline). $\mathrm{CO}$ after rowing was significantly higher compared with after cycling $(\mathrm{P}<0.05)$ (Fig. 2C).

In contrast, systolic and diastolic BP were comparable at rest and after both types of exercise ( $\mathrm{P}>0.05$ for all comparisons) (Table 1).

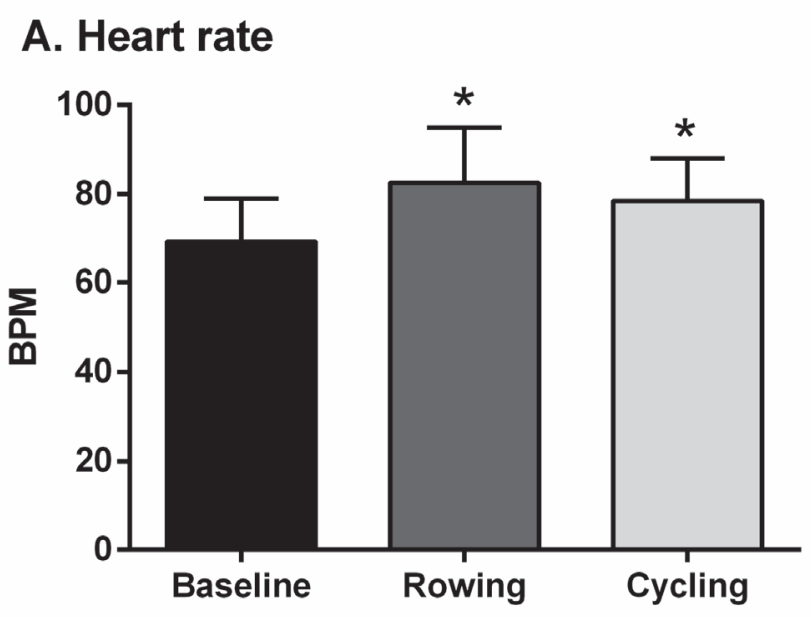

\section{B. Stroke Volume}
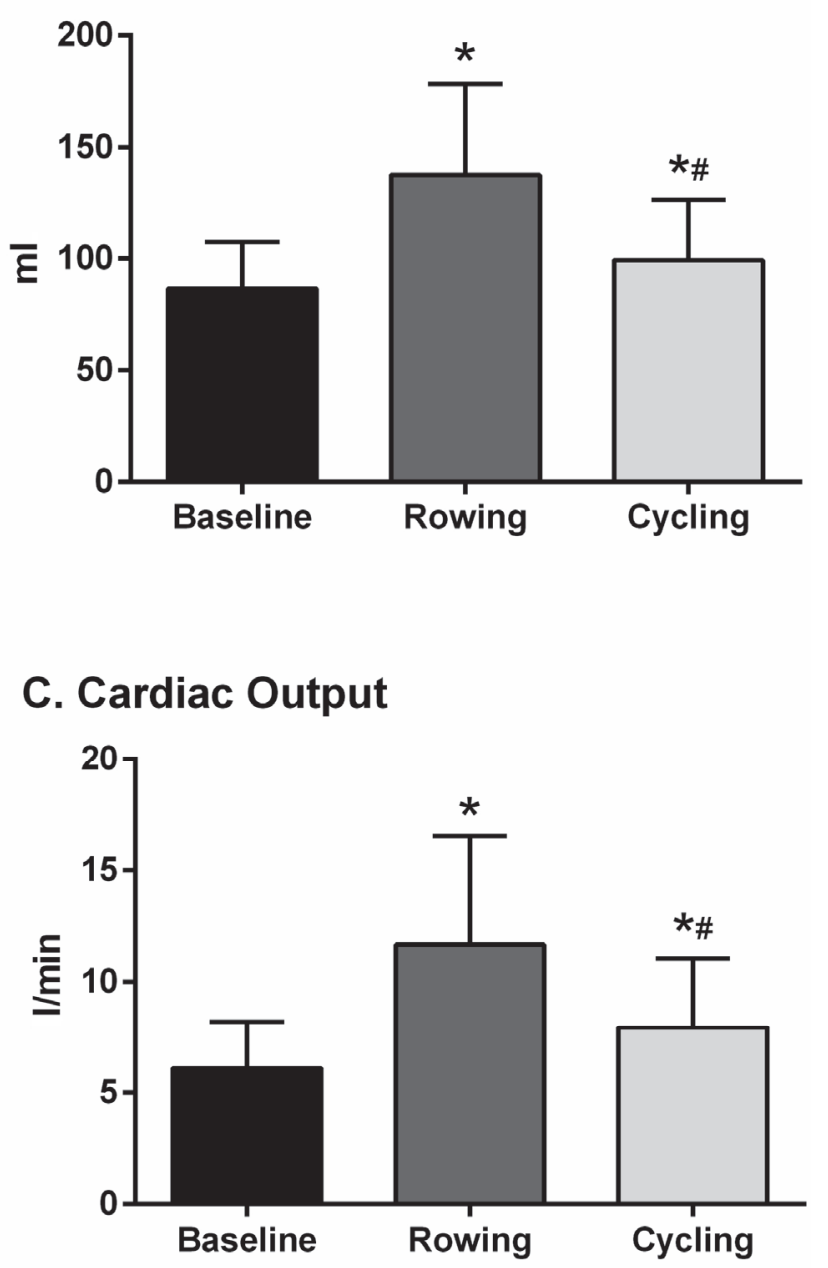

Fig. 2. Hemodynamic parameters measured at rest (baseline) and after rowing or cycling exercise ( $2 \mathrm{~W} / \mathrm{kg}$ for $2 \mathrm{~min}$ ). A. Heart rate values; B. Stroke volume values; $\mathbf{C}$. Cardiac output values. Data presented as mean $\pm \mathrm{SD} . * \mathrm{P}<0.05$ versus baseline; ${ }^{\#} \mathrm{P}<0.05$ versus rowing 
Table 1. Blood pressure (BP) values measured at baseline, after rowing and after cycling exercise.

\begin{tabular}{lllll}
\hline BP & Baseline & Rowing & Cycling & P \\
\hline Systolic & $135.0 \pm 12.8$ & $138.9 \pm 9.9$ & $136.8 \pm 13.2$ & NS \\
Diastolic & $78.0 \pm 8.4$ & $70.5 \pm 7.4$ & $75.1 \pm 6.8$ & NS \\
\hline
\end{tabular}

Data presented as mean \pm SD. NS: Not statistically significant

\section{Discussion}

The primary observation of the present study was that SV and $\mathrm{CO}$ following rowing were significantly higher compared with cycling. Although differences in $\mathrm{SV}$ and $\mathrm{CO}$ were observed, $\mathrm{HR}$ and $\mathrm{BP}$ remained comparable after rowing versus cycling. It can, therefore, be hypothesized that rowing more intensively stimulates cardiac contractility and decreases peripheral vascular resistance compared with cycling.

Rowing and cycling represent typical strength and endurance sports involving combined dynamic and static exercise of large muscle groups. During maximal exercise, systolic HR increases to near-maximal values, with peak systolic blood pressure reaching $>200 \mathrm{~mm} \mathrm{Hg}$ (Clifford et al. 1994). Meta-analyses investigating the structure of athletes' hearts demonstrated slightly divergent cardiac adaptations among dynamic, static and intermediate sports (Kuchynka et al. 2010, Pluim et al. 2000). The combined endurance- and strength-trained cyclists and rowers exhibited a significant increase in relative wall thickness and the highest increase in left ventricular internal diameter. This observation is largely in accordance with the results reported by Spirito et al. (1994), who ranked 27 sports according to their effects on left ventricular diastolic cavity dimension and left ventricular wall thickness. Rowing was ranked first according to the effect on left ventricular wall thickness (with cycling ranked second), and cycling was ranked first according to the effect on left ventricular internal dimension (with rowing ranked seventh). Our results suggest that the hemodynamic effect of cycling and rowing also differs during submaximal acute exercise in untrained subjects. It appears, therefore, that rowing confers a more intensive load on the cardiovascular system compared with cycling. The $\mathrm{CO}$ and $\mathrm{SV}$ are determined by preload, contractility and afterload. Our study was, however, not designed to show whether the differences in $\mathrm{CO}$ and $\mathrm{SV}$ between rowing and cycling are caused more by increased contractility or by decreased peripheral vascular resistance.

$\mathrm{CO}$ at rest and during submaximal exercise has been evaluated with acceptable reliability using a series of invasive and noninvasive techniques (reviewed in Warburton et al. 1999b,c). The 'gold standard' measures of cardiac function are considered to be the direct Fick and dye-dilution methods. These have been widely demonstrated to result in accurate and reliable determination of $\mathrm{CO}$ during resting and submaximal exercise conditions. Thermodilution has also been considered to be a relatively appropriate method for the determination of $\mathrm{CO}$; however, it has recently been criticized due to the nature of the measure and its inaccuracy during strenuous exercise. Various noninvasive measures of $\mathrm{CO}$, such as foreign gas measures and the indirect Fick $\left(\mathrm{CO}_{2}\right)$ method, have been developed to overcome the problems associated with the 'gold standard'. However, very few techniques are suitable for maximal exercise conditions. It is possible that only the foreign gas rebreathing method (using acetylene) meets the criteria of being noninvasive, simple to use, reliable over repeated measurements, accurate and useful during maximal exercise.

Recently, new methodologies have been developed to measure $\mathrm{CO}$ during exercise conditions. Although not as common as the acetylene and $\mathrm{CO}_{2}$ rebreathe method, these techniques have increasingly gained favor in exercise physiology and sport cardiology settings, and include Doppler echocardiography, impedance cardiography and radionuclide scintigraphy. However, the cost of use and technological limitations during maximal exercise have prevented these techniques from replacing the conventional measures of $\mathrm{CO}$ during exercise conditions. We used noninvasive method of hemodynamic measurements based on the pulse-wave analysis. The accuracy of these measurements is lower than that of invasive methods (Pucci et al. 2013); however, all measurements were performed using the same method and, therefore, the pattern of differences would likely be consistent even when the exact values are shifted.

Our study had several limitations, mostly caused by limited number of subjects enrolled and method of measurement. It also cannot be excluded that the plateau of $\mathrm{CO}$ and $\mathrm{SV}$ was not reached during the $2 \mathrm{~min}$ period of each type of exercise and the differences may be, therefore, caused by different slope of increase. Confirmation of our results by other method of 
hemodynamic measurement is needed, however, the potentially harmful effects of more invasive methods limit the performance of studies involving these methods in young healthy individuals.

In conclusion, our data suggest that rowing increases SV and $\mathrm{CO}$ to a greater extent than cycling, whereas HR and BP are not different between these types of exercise. Further studies, using different methods to measure hemodynamic variables and involving larger study populations, are needed to confirm our observation.

\section{Conflict of Interest}

There is no conflict of interest.

\section{Acknowledgements}

This study was supported by the grant from the Czech Ministry of Health, Nr. 12153, by the Institutional grant $\mathrm{MH} \mathrm{CZ} \mathrm{-} \mathrm{DRO} \mathrm{(Nemocnice} \mathrm{Na} \mathrm{Homolce} \mathrm{-} \mathrm{NNH,}$ 00023884) and by the Institutional grant RVO: 67985823. Results of the present study do not constitute endorsement by ACSM.

\section{References}

BAGgiSH AL: The athlete's heart. In: Cardiac Adaptation. Advances in Biochemistry in Health and Disease. OSTADAL B, DHALLA NS (eds), Springer Science and Business Media. New York, 2013, pp 289-302.

CLIFFORD PS, HANEL B, SECHER NH: Arterial blood pressure response to rowing. Med Sci Sports Exerc 26: 715 $719,1994$.

KUCHYNKA P, PALECEK T, VILIKUS Z, HAVRANEK S, TABORSKA K, LOUCH WE, LINHART A: Cardiac structural and functional changes in competitive amateur cyclists. Echocardiography 27: 11-16, 2010.

MORGANROTH J, MARON BJ, HENRY WL, EPSTEIN SE: Comparative left ventricular dimensions in trained athletes. Ann Intern Med 82: 521-524, 1975.

NAYLOR LH, GEORGE K, O'DRISCOLL G, GREEN DJ: The athlete's heart: a contemporary appraisal of the 'Morganroth hypothesis'. Sports Med 38: 69-90, 2008.

PELLICCIA A, MARON BJ, SPATARO A, PROSCHAN MA, SPIRITO P: The upper limit of physiologic cardiac hypertrophy in highly trained elite athletes. N Engl J Med 324: 295-301, 1991.

PLUIM BM, ZWINDERMAN AH, VAN DER LAARSE A, VAN DER WALL EE: The athlete's heart. A meta-analysis of cardiac structure and function. Circulation 101: 336-344, 2000.

PUCCI G, CHERIYAN J, HUBSCH A, HICKSON SS, GAJENDRAGADKAR PR, WATSON T, O'SULLIVAN M, WOODCOCK-SMITH J, SCHILLACI G, WILKINSON IB, MCENIERY CM: Evaluation of the Vicorder, a novel cuff-based device for the noninvasive estimation of central blood pressure. J Hypertens 31: 77-85, 2013.

ROWELL LB, SHERIFF DD, WYSS CR, SCHER AM: The nature of the exercise stimulus. Acta Physiol Scand Suppl 556: 7-14, 1986.

SPIRITO P, PELLICCIA A, PROSCHAN MA, GRANATA M, SPATARO A, BELLONE P, CASELLI G, BIFFI A, VECCHIO C, MARON BJ: Morphology of the "athlete's heart" assessed by echocardiography in 947 elite athletes representing 27 sports. Am J Cardiol 74: 802-806, 1994.

WARBURTON DE, GLEDHILL N, JAMNIK VK, KRIP B, CARD N: Induced hypervolemia, cardiac function, VO2max, and performance of elite cyclists. Med Sci Sports Exerc 31: 800-808, 1999a.

WARBURTON DE, HAYKOWSKY MJ, QUINNEY HA, HUMEN DP, TEO KK: Reliability and validity of measures of cardiac output during incremental to maximal aerobic exercise. Part I: Conventional techniques. Sports Med 27: 23-41, 1999b.

WARBURTON DE, HAYKOWSKY MJ, QUINNEY HA, HUMEN DP, TEO KK: Reliability and validity of measures of cardiac output during incremental to maximal aerobic exercise. Part II: Novel techniques and new advances. Sports Med 27: 241-260, 1999c. 